titious matters; to relieve the momentary depression, where it occurs, by diffusable stimulants; and finally, to restore proper performance of the digestive functions, and in every way improve the general health.

9th. The existence of hysterical symptoms in males is rendered indisputable.

\section{AFFECTION OF THE EYE}

SUESIDING ALWAYS ON THE

ADMISSION OF LIGH'I' By W. F. Barlow, Esq., Writtle.

DAvid Brewster, an old man, seventyeight years of age, has been troubled for about three months with the following symptoms :-

In the evening, when twilight is fast merging into darkness, or during the night, he is seized with a sharp darting pain, seated in the eyes, and running along the eyebrows, attended with various Iuminous appearances, rision of confused objects, such as floating clouds, \&c., and a perpetual and incontrollable winking, whilst there is a general tremor and restlessness of the frame, together with an inexplicable feeling of alarm. The attack (which has no fixed time for its occurrence, but which sometimes happens not less frequently than four times between night and morning) persists until a candle is brought into the room, when it ceases instantly.

This is the strange feature of the case, for darkness is so proverbially considered to palliate almost every painful affection of the eye, that it seems a surprising occurrence for one to take place which never supervenes but in the absence of light, and which immediately vanishes on light being restored. With this exception there is nothing in the malady worthy of particular mention, and I only describe it with a view to show how the retina, the exalted sensibilities of which are so generally allayed by a darkened apartment, may yet, as in the foregoing in. stance, obtain relief by an exposure of the eye to its proper stimulus. I regard the case as being purely nervous in its character. There is no derangement of the digestive or the circulatory functions, no disturbance of the sensorium, and no apparent disorder of the constitution.

Writtle, near Chelmsford,

Dec. 12, 1842.

SMALL TOURNIQUETS IN PHLEBOTOMY.

To the Editor.-Sir: The following case illustrates my observations on the advantages of the tourniquet over the common ligature in phlebotomy. Instances occur in very corpulent patients where the ope- rator has either failed to extract blood, or, by making a hazardous plunge with the lancet, has penetrated both sides of the vein. The consequences are well known. A mother of twenty-two children was so corpulent that no vein could be felt until the tourniquet was applied, when the median vein rose sensibly to the finger, and I opened it with facility, a copious quantity of blood flowing from a large orifice. The great advantage of the tourniquet consists in its graduated pressure, an effect that will always render it superior to the common ligature, according to my own experience and opinion. My tourniquet is the common one, reduced to the imallest size, containing a red woollen fillet, of a little more than half an inch in width, and always accompanies my case of lancets. I have the honour to remain your most obedient servant,

Primrose Lyon, Surgeon, R.N.

Hyde-pl., Clarendon-rd., Jersey, Dec. 12, 1842 .

\section{NURSERY TREATMENT OF INFANTS,}

\section{SUBMITTED TO PRINCE ALBERT.}

To the Editor of THE LANCET.

Sir,-Whaving been strongly urged to give publicity to the observations upon the nursery treatment of infants which I lately had the honour of submitting to his Royal Highness Prince Albert, I herewith transmit an outline of them, hoping that it may benefit the rising generation. After twenty-six years' extensive practice as a surgeon. accoucheur, I believe that at least half of the infants who die within a year after ueaning might be saved by giving them the milk of one cow, and one only. I remain, \&c.

Joshua Wadoington, M.R.C.S.,

Consulting Surgeon of the Royal SeaBathing Infirmary.

Marine-terrace, Margate,

Dec. 16, 1842.

No other kind of milk to be given to an infant in addition to the milk of the mother or wet-nurse.

The less rocking the better.

When asleep, to be laid upon its right side.

The best food is "Lemann's biscuit-powder," soaked for twelve hours in cold springwater, then boiled for half an hour, not simmered, or it will turn sour. Very little sugar to be added to the food, and then only at the time when given.

Sweets, of every kind, are most injurious, producing acidity, flatulency, and indigestion, sores in the month, and disordered secretions.

An infant will take medicine the more readily if made lukewarm in a cup placed in hot-water, adding a very little sugar when given. 